\title{
Species distribution model of invasive alien species Acacia nilotica for Central-Eastern Indonesia using Biodiversity Climate Change Virtual Laboratory (BCCVL)
}

\author{
SUTOMO $^{1,2, \boldsymbol{v}}$, EDDIE VAN ETTEN ${ }^{1}$ \\ ${ }^{1}$ School of Science, Edith Cowan University, Joondalup Drive, Joondalup 6027 Perth Western Australia. ^email: tommo.murdoch@ gmail.com \\ ${ }^{2}$ Bali Botanical Garden, Indonesian Institute of Sciences (LIPI), Candikuning, Baturiti, Tabanan, 82191 Bali, Indonesia
}

Manuscript received: 6 January 2017. Revision accepted: 23 April 2017

\begin{abstract}
Sutomo, Van Etten E. 2017. Species distribution model of invasive alien species Acacia nilotica for Central-Eastern Indonesia using Biodiversity Climate Change Virtual Laboratory (BCCVL). Trop Drylands 1: 36-42. Climate change may facilitate alien species invasion into new areas. This study uses Biodiversity and Climate Change Virtual Laboratory to develop a species distribution model (SDM) of Acacia nilotica (L.) Willd. ex Delile. based upon its naturalized distribution to project the potential distribution of A. nilotica throughout tropical environment of Indonesia under current and future climate conditions. Global Biodiversity Information Facility (GBIF) database was utilized to obtain the species occurrences data. The climate factors were precipitation and temperature layers, available in WorldClim current conditions (1950-2000) at 2.5 arcmin. We used Generalized Linear Model. The result was then projected to the year 2045 using RCP 8.5 greenhouse gas emissions scenarios to influence the climate model (CSIRO Mark 3.0. with 30", resolution). Final results show that global climate change is likely to increase markedly the potential distribution of $A$. nilotica in Indonesia. By the year 2045, A. nilotica is most likely to spread to eastern parts of Indonesia. In general, our model performance is good $(\mathrm{AUC}=0.82)$, however, like many other SDMs, it does not take into account biotic interactions as well as other environmental factors. Nonetheless, climatic suitability is an essential requirement for successful establishment of an invasive species and species distribution models that can disclose general patterns and convey useful estimates.
\end{abstract}

Keywords: Acacia nilotica, invasive alien species, species distribution model, climate change

Abbreviations: GCM: Global Climate Change Model, SDM: Species Distribution Model, BCCVL: Bidoversity and Climate Change Virtual Laboratory, GBIF: Global Biodiversity Information Facility, GLM: Generalized Linear Model, AUC: Area Under the Curve, ROC: Receiver-Operating Characteristics, TPR: True Positive Rate, TNR: True Negative Rate, HSI: Habitat Suitability Index, IAS: Invasive Alien Species, NTT: Nusa Tenggara Timur

\section{INTRODUCTION}

Acacia nilotica (L.) Willd. ex Delile is a small tree species widespread in the northern savanna regions of Africa, and its range extends from Mali to Sudan and Egypt. A. nilotica is known to be abundant in its native habitat in Africa (Brenan 1983), but no study has been specifically focused on this species. Outside of its original distribution, A. nilotica is considered an invasive alien species or noxious weed. In Australia, this species is found to spread along the western part of Queensland while in other states such as Western Australia, New South Wales, Adelaide and Northern Territory, this species was found in only a few numbers (Reynolds and Carter 1990). A. nilotica is considered to have a negative impact on savannas since adult trees of this species are tolerant to fire (Radford et al. 2001). A previous study by Burrows et al. (1991) observed that on Mitchell grasslands in Australia, A. nilotica was invading the grassland and forming thorny thicket formations.

A. nilotica was first introduced in Indonesia in the late 1960s in Baluran National Park in East Java. The original purpose of introducing this species was to create fire breaks to prevent the fire from spreading from Baluran Savanna into the surrounding forests. Along the time, the rapid spread of $A$. nilotica has threatened the existence of Baluran Savanna which has caused changes in some areas of the national park from open savannas to the more closed canopy areas (Djufri, 2004). If unabated, the continuing spread and over dominance of $A$. nilotica could shift the savanna into another ecosystem state such as the secondary/dry forest.

It was predicted by Global Climate change Models (GCMs) (IPCC 2007) that by the end of 21st century, global warming would cause an increase of mean temperature of about $3-4{ }^{\circ} \mathrm{C}$, a decrease of rainfall of about $30-40 \%$, and significant changes in seasonal as well as severe weather events. Molloy et al. (2013) stated that, at a regional scale, most species and ecological communities exist within a definable bioclimatic niche, where precipitation and temperature are among a set of variable climatic parameters that control the habitat values. If these variables change, then the habitat value for that area will also change. The task of understanding how species and communities respond to changes is crucial. Climate change may facilitate alien species invasion into new areas, 
particularly for species from warm native ranges introduced into areas currently marginal for temperature (Sheppard et al. 2014).

Species distribution model or SDM has the capability to assess current distribution and simulate climate-induced range shifts under different global change scenarios at the single-species and community levels (Crego et al. 2014). Therefore, the model could identify areas at risk of further invasion by invasive alien species so that pre-emptive actions could be undertaken in a plausible approach Franklin et al. (2014) described steps in species distribution modelling as follows. Species occurrence data (such as presence-only, presence-absence or abundance) are the response variable, and environmental variables are the predictors used in a multiple regression-like modelling framework. The model can be fitted in data space using a wide variety of statistical learning methods. Estimated parameters are then applied back to environmental data layers (mapped grids) to predict the probability of species occurrences in geographical space.

SDMs has enabled conservationists to predict future landscape and has been applied in many areas of research such as for invasive species management (Webber et al. 2011), conservation and reintroduction of endangered species (Adhikari et al. 2012; Molloy et al. 2016), adaptive management of protected areas (Mairota et al. 2014), restoring landscapes connectivity (Gurrutxaga and Saura 2014) and many others. Molloy et al. (2013) did SDMs using bioclimatic variables to determine the impacts of a changing climate on the western ringtail possum (Pseudocheirus occidentals; Pseudocheiridae) in Southwest Australia. Kritikos et al. (2003) conducted SDM using CLIMEX and predicted the potential distribution under future climate change scenarios for invasive alien species A. nilotica subspecies indica in Australia. Their results showed that the potential distribution of the species in Australia under current climatic conditions is vast and far greater than the current distribution. The authors also highlighted the impact of global climate change that may likely increase the species potential distribution in Australia and significantly increase the area at risk of invasion.

This study used Biodiversity and Climate Change Virtual Laboratory, BCCVL (http://www.bccvl.org.au/) (Hallgren et al. 2016) to develop a species distribution model of $A$. nilotica based upon its naturalized distribution in and outside of Indonesia to project the potential distribution of $A$. nilotica throughout Indonesia under current climate conditions and to assess the sensitivity of this distribution to climate change. BCCVL is a unique cloud-based virtual laboratory that provides access to numerous species distribution modelling tools; a large and growing collection of biological, climate, and other environmental datasets; and a variety of experiment types to conduct research into the impact of climate change on biodiversity (Hallgren et al. 2016). Understanding the likely potential distribution of this obnoxious plant under current and future climate scenarios will help policy makers and land managers to set up proper approaches to handling the invasion.

\section{MATERIALS AND METHODS}

\section{Procedures}

We made use of the Biodiversity and Climate Change Virtual Laboratory, BCCVL (http://www.bccvl.org.au/) to conduct the modelling analysis (Hallgren et al. 2016). Global Biodiversity Information Facility, GBIF (http://www.gbif.org/) was utilized to obtain the species occurrence data for $A$. nilotica (GBIF 2016). Global Biodiversity Information Facility (GBIF) is an international open data infrastructure funded by governments. Currently, there are various subspecies of $A$. nilotica listed in the GBIF. We chose to use the common A. nilotica (L.) Willd. ex Delile. as it is recorded to be present at Baluran National Park in East Java, Indonesia (Tjitrosoedirdjo 2008). The GBIF database has about 879 occurrence records of $A$. nilotica with 232 occurrences were geo-referenced. This dataset was then imported into Biodiversity and Climate Change Virtual Laboratory (BCCVL). This data of species occurrence acted as the response variable, and the predictors were the environmental variables.

In this simulation, we used WorldClim current conditions (1950-2000) at 2.5 arcmins as environmental predictors. The WorldClim collections consist of an array of global climate layers (climate grids) covering all global land areas except Antarctica. They are in the latitude /longitude coordinate reference system (not projected) and the datum is WGS84. The average monthly climate data from weather stations were used to produce the data layers. The WorldClim collection is composed of two main components, i.e. the current climate and the future climate (Hijmans et al. 2005). We selected precipitation and temperature variables because they represent important factors determining vegetation range and abundance (Krebs 1985; Van Steenis 1972), and that A. nilotica SDM in Australia correspond well with these climate variables (Kriticos et al. 2003). We selected seven climate variables namely maximum temperature of warmest month (B05), minimum temperature of coldest month (B06), mean temperature of wettest quarter (B08), mean temperature of driest quarter (B09), precipitation of wettest month (B13) and driest month (B14), precipitation seasonality (B15) and temperature seasonality (B04). Extreme variables are better represented by the ranges of conditions where species can occur (Crego et al. 2014).

\section{Data analysis}

The Species Distribution Model Experiment (SDM) allows us to investigate the potential distribution of a species under current climatic conditions. The BCCVL currently provides 17 different algorithms across four different categories to run species distribution model (e.g. profile model, statistical regression model, machine learning model and geographic model). In this study, we used statistical regression model namely Generalized Linear Model (GLM) to process our SDM. The GLM was used for the reason that the model accommodates regression model for data with a non-normal distribution, fitted with maximum likelihood estimation. This model produces estimates of the effect of different environmental 
variables on the distribution of a species. The model uses all the data available to estimate the parameters of the environmental variables and construct a function that best describes the effect of these predictors on species occurrence. The suitability of a particular model is often defined by specific model assumptions. The prediction is visualized as the suitability of a grid cell on a scale from 0 to 1 , where 0 refers to very low suitability and 1 refers to very high suitability. Results from BCCVL are tiff file which then processed further using ARC MAP 10.1. Raster value was created and classified, and then different color was given to easily enable us to different areas with different habitat suitability index.

The primary output of an SDM was a map that showed the predicted distribution of A. nilotica under the baseline conditions. The prediction is not really refer to where the species occurs, but rather the distribution of suitable habitat as defined by the environmental variables (in this case current climate condition) included in the model. The second output was response curve. The response curve that shows the relationship between the probability of occurrence for a species and each of the environmental variables was modelled according to the method of Richmond and Huijbers (2016). Model robustness was evaluated using the AUC (Area Under the Curve) of the ROC curve (Receiver-Operating Characteristics), which is a nonparametric threshold-independent measure of accuracy commonly used to evaluate species distribution model (Bertelsmeier and Courchamp 2014). The ROC plot is a graph of the False Positive Rate (1-Specificity) on the $\mathrm{x}$-axis and the True Positive Rate (Sensitivity) on the y-axis plotted across the range of threshold probability values. The value for ROC is the area under the curve (AUC). A value of 0.5 represents a random prediction, and thus values above 0.5 indicate predictions better than random. We interpreted the AUC score as follow: a value above 0.9 is excellent, good $0.9>\mathrm{AUC}>0.8$, fair $0.8>\mathrm{AUC}>0.7$, poor $0.7>$ AUC $>0.6$ and fail $0.6>$ AUC $>0.5$ (Crego et al. 2014; Sweets 1988).

Further analysis was conducted to investigate the distribution of A. nilotica under potential future climatic conditions. In BCCVL this is named the Climate Change Experiment. Climate change experiment obtains a prediction of where A. nilotica could occur in the future under a particular climate change scenario. This analysis uses the results from the SDM experiment and projects that distribution for a certain year in the future with the climate information from one of several climate models. In this study, we selected RCP 8.5 (business as usual) greenhouse gas emissions scenarios to influence the climate model; in this case, we used CSIRO Mark 3.0 with $30^{\prime \prime}(\sim 1 \mathrm{~km})$ resolution. We projected our SDM to the year 2045.

\section{RESULTS AND DISCUSSION}

\section{Results}

The potential distribution of A. nilotica in Indonesia under current climatic conditions is greater than the current distribution. Under the current climate, it is predicted that A. nilotica is most likely to spread to eastern parts of Indonesia although some parts of Java especially in the south coast of East and Central Java, also are predicted to be suitable for $A$. nilotica (Figure 1). To the eastern Indonesia, $A$. nilotica is predicted to be suitable to inhabit several sites in south-eastern Bali, southwest of Lombok, south-eastern Sumba, most of Kupang District on West side of Timor Island, and also some part of along south coast of West Papua. In West Papua, the species is predicted to be potentially suitable to inhabit $( \pm 0.64)$ southern coast along Merauke. Also interesting to note that small island just off the coast between Merauke and Tual is predicted by the model to be potentially suitable $( \pm 0.61)$ habitat for this invasive species (Figure 1). There is a trend of increasing value of mean suitability index ( 0.47 to 0.6$)$ as we moved from central to eastern part of the archipelago (Figure 2).

Global climate change is likely to increase the potential distribution of $A$. nilotica in Indonesia, increasing the area at risk of invasion. Bali Island, Lombok Island (West Nusa Tenggara NTB), Sumba Island and Kupang (East Nusa Tenggara), as well as West Papua, have increased the area at risk of invasion. On Sumba Island (Figure 3), the current prediction has one area (Baing District in the south-eastern Sumba) where the HSI (Habitat Suitability Index) is in the range of $0.7-0.9$, and by 2045 it is predicted that Melolo Sub-district in north-eastern Sumba will also have similar HSI to Baing District. For Kupang on the west side of Timor Island, it is detected that there will be an increase in the HSI around the Tenau and Oesau Sub-districts by 2045 (Figure 3). In general, our model performance is of good results as AUC values (0.82) are still in the range of 0.8 0.9 (Figure 5).

All of the chosen climate variables are responsive to $A$. nilotica distribution (Figure 4). The response curves in this plot show that the probability of occurrence of $A$. nilotica follows an optimum curve for the specific variable. $A$. nilotica occurs in areas that are very seasonal. It can grow in places with low rainfall and high rainfall $(10-150 \mathrm{~mm}$ month $^{-1}$ ). It does not like extreme cold or frost, it can grow in areas where the minimum temperature of the coldest month is around 12 to $13{ }^{\circ} \mathrm{C}$ and it also grows in areas where the maximum temperature of the warmest month is around $\sim 35^{\circ} \mathrm{C}$.

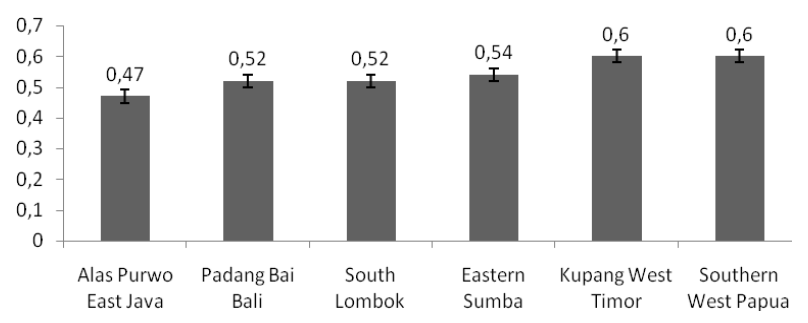

Figure 2. Mean of suitability index value for Acacia nilotica model using GLM in BCCVL. 


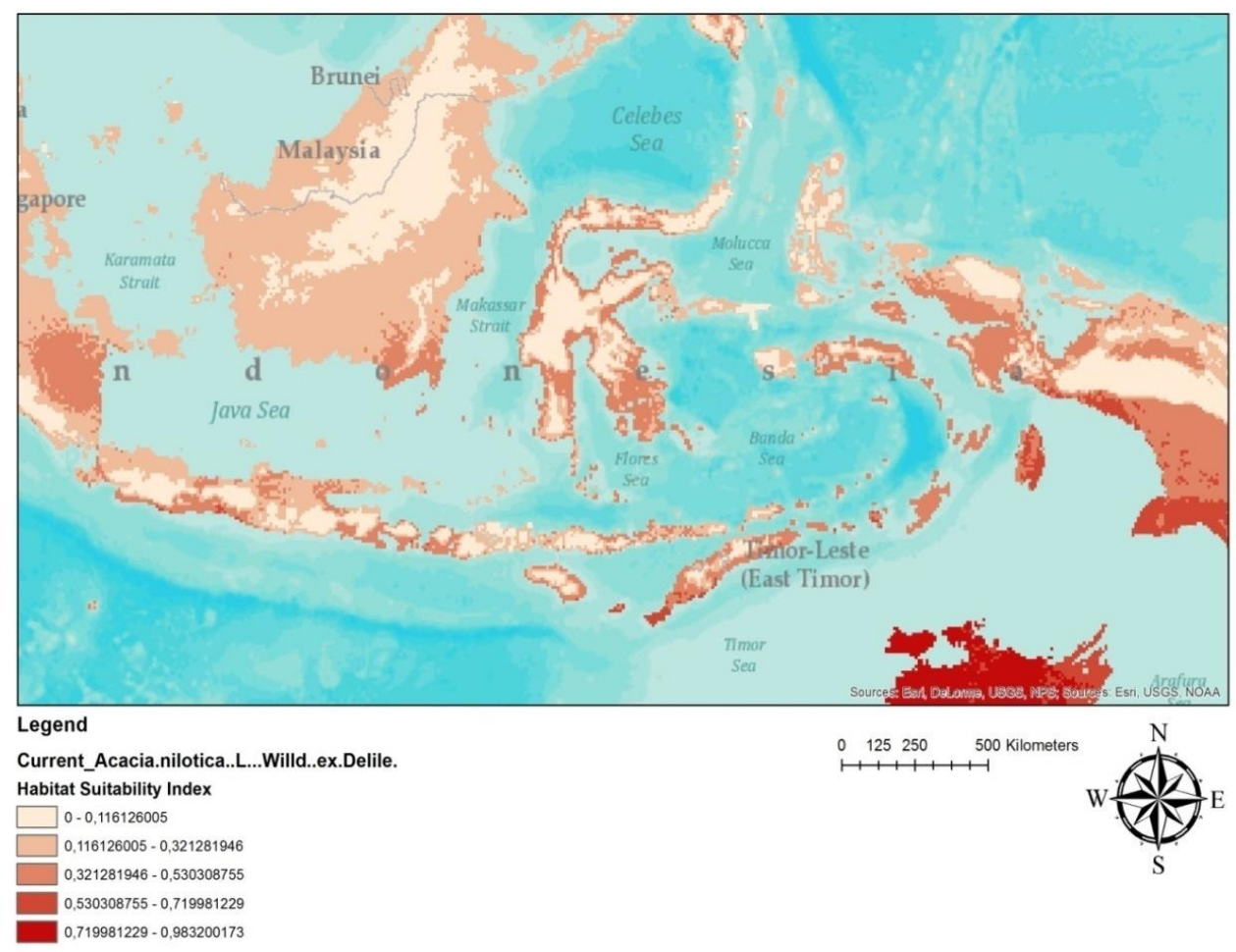

Figure 1. Predicted current distribution (habitat suitability map) of Invasive Alien Species (IAS) Acacia nilotica in Indonesia under current climate conditions using Generalized Linear Model (GLM) algorithm in BCCVL. Darker areas represent a higher likelihood that the species can occur.

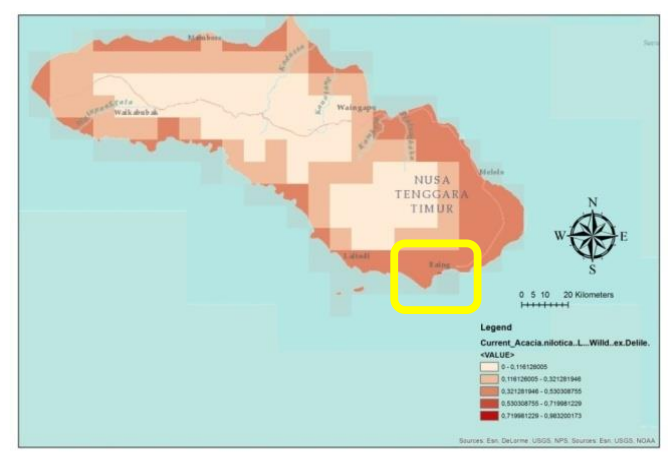

Sumba, Current

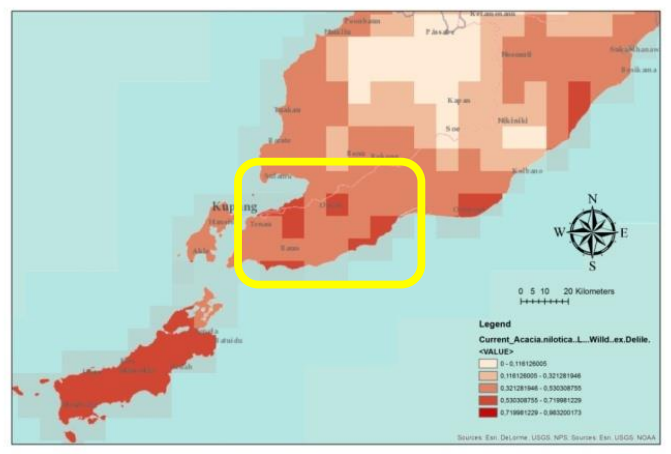

Kupang, Current

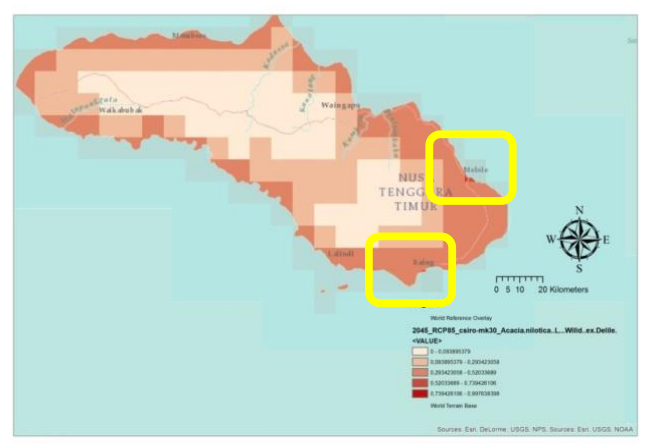

Sumba, 2045

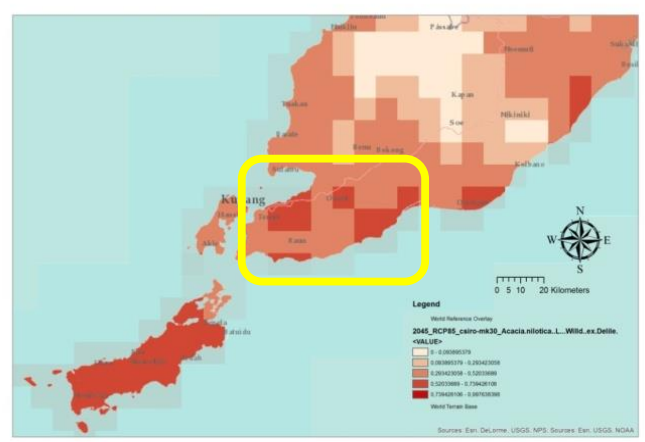

Kupang, 2045

Figure 3. Projection of Acacia nilotica species distribution/Habitat Suitability Index (HSI) on Sumba Island and Kupang, East Nusa Tenggara Province, Indonesia by 2045. Left: Predicted current distribution/current HSI. Right: Projected distribution/projected HSI in 2045. Yellow square to show to emphasize where the HSI changed. 

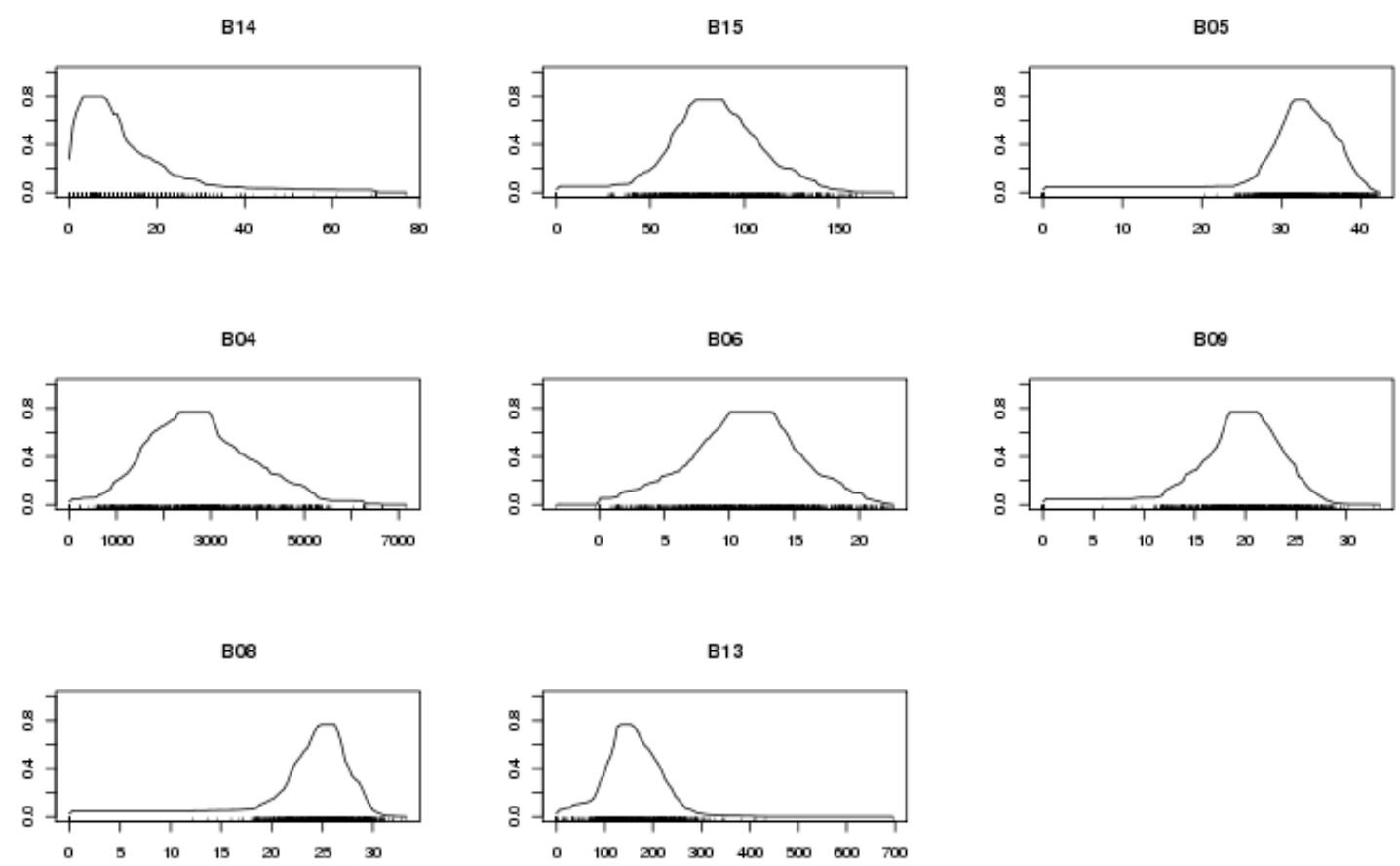

Figure 4. The response curve for Acacia nilotica distribution model. B05: maximum temperature of warmest month, B06: minimum temperature of coldest month, B08: mean temperature of wettest quarter, B09: mean temperature of driest quarter, B13: precipitation of wettest month, B14: precipitation of driest month, B15: precipitation seasonality and B04: temperature seasonality

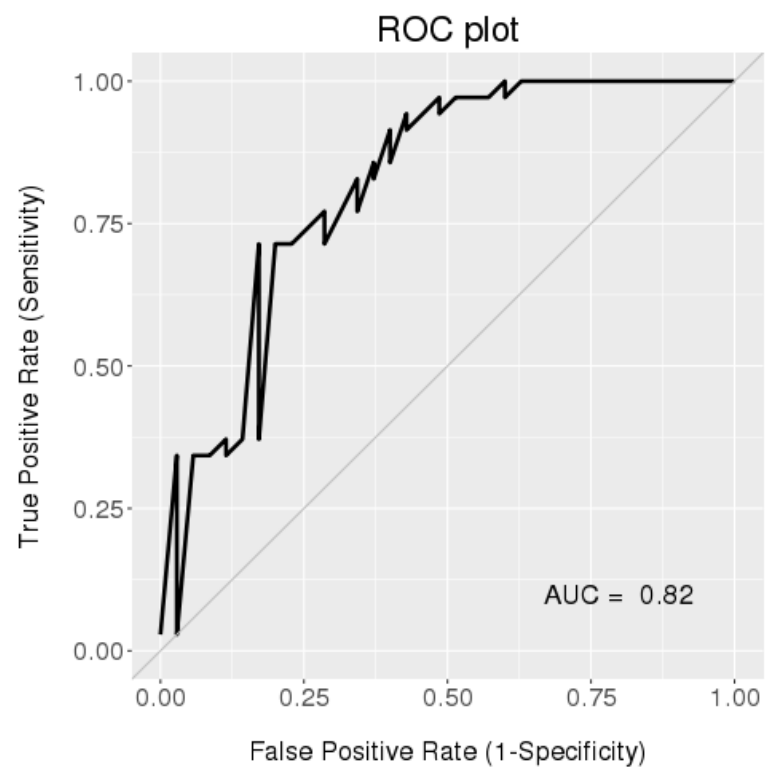

Figure 5. ROC plot which shows AUC value for Acacia nilotica model using GLM in BCCVL.

\section{Discussion}

The study shows that areas with the highest concentration of potential invasion of $A$. nilotica in Indonesia are mainly located along the coastline, especially in the southeast of Indonesia archipelagoes such as East Java, Bali, Lombok, Sumba, Kupang and West Papua. This result agrees with the current location of $A$. nilotica ever recorded in Indonesia in the literature and is also based on our encounter in the field. Fisher (2010) mentioned the presence of A. nilotica in savanna in Kupang East Nusa Tenggara Indonesia in 2010. Additionally, on our field trip to Kupang in 2015, we also noted our encounter with this thorny Acacia in savanna near a roadside to Tablolong Beach. In his expedition in 2010, Arinasa (personal communication) noted the presence of A. nilotica in Bali Barat National Park with the herbarium, seed and cone samples were processed and registered at the Hortus Botanicus Baliensis in Bali Botanical Garden. Previous work by Tjitrosoedirdjo (2008) also reported the spread of the species in other islands outside Java such as Timor and Papua. A. nilotica was reported as dominant colonizer at Baluran National Park in East Java Province and Wasur National Park in Papua (Tjitrosoedirdjo 2008). However, at a local scale, the model did not recognize Baluran National Park, at the north tip of East Java Province with high HSI and thus underestimate the occurrence of A. nilotica in this locality where it has been a problem for more than 20 years.

The current SDM model, when overlaid with other environmental and landscape layers, could have provided more insight. A. nilotica is found in savannas and grasslands at various soil types and various temperatures but is reported to be very sensitive to frost but will grow in an area where the mean monthly temperature of the coldest month is $16^{\circ} \mathrm{C}$ (FAO 2014). This is in line with our findings. Our model shows that $A$. nilotica habitats are very seasonal; it follows an optimum curve for the selected 
temperature and precipitation with a high probability in areas that have a temperature between 13 and $35{ }^{\circ} \mathrm{C}$. This factor has some connection with land use where this species occurs which is mostly in savanna or grassland as places that have high seasonality as can be seen in Baluran National Park East Java and on Sumba Island (Bond and Keeley 2005; Sutomo and van Etten 2016). A. nilotica was not only found in a savanna ecosystem with the volcanicorigin type of soil as in Baluran National Park (Sutomo 2015), but also in other savannas where the soils are not of volcanic origin such as savannas in Sumba and Kupang in NTT Province. Savanna is the dominant type of land cover on Sumba Island and it is also the most burnt (Sutomo and van Etten 2016, unpublished data). Sumba Island receives an average annual precipitation of $900 \mathrm{~mm}$ and experience more than five months of the dry period and is located in region A (southern monsoonal region) of Indonesian climate classification region (Aldrian and Susanto 2003; Hanifah 2014). The average high temperature and low rainfall with prolonged dry season as well as local practices caused fires is more prominent in this landscape (Fisher et al. 2006; Monk et al. 2000). East Sumba District was where most of the dominant fire hotspots were detected (Sutomo and van Etten 2016, unpublished data). Our SDM also found that high HSI areas were found in East Sumba and that by 2045 the HSI is more likely to increase.

Our model projection shows a fairly small increase in potential distribution of $A$. nilotica in south-eastern parts of Indonesia by 2045 which is reasonable for a tropical climate. Our model had moderate to good performance (AUC) but yet they share a certain number of fundamental assumptions common to all species distribution models. These models do not take into account biotic interactions or microclimate conditions which may decide at a very local scale whether or not a particularly invasive species eventually becomes established in a given area (Bertelsmeier and Courchamp 2014). Nonetheless, climatic suitability is an essential requirement for successful establishment of an invasive species and species distribution models can disclose general patterns and convey useful estimates (Bertelsmeier and Courchamp 2014).

The SDM model, however, does not take into account biotic interactions and at a local scale; this interaction has been proved to have significantly affected the species of interest. For example, the interaction between A. nilotica with herbivores has benefited $A$. nilotica. The lowland savanna area is an important habitat for big mammal grazers such as wild buffalo, deer and banteng. Invasion of A. nilotica in these areas may have caused changes in the feeding behavior of these grazers and may have been causing the spread of this invasive species further in the Baluran National Park. A. nilotica is also unpalatable by the herbivores as this plant possesses thorny spikes on its branches which make it difficult for the herbivores to consume the leaf. However, the pods that drop to the ground are usually consumed by herbivores during the prolonged dry period when fresh shoots and grasses are scarce. At the end of the wet season toward the dry season, mature A. nilotica pods drop from the trees and are consumed by herbivores such as water buffalo (Tjitrosoedirdjo et al. 2013) that spread A. nilotica further in the national park. Sutomo et al. (2015) found that there was a large number of seeds found in buffalo dung. In approximately 100 grams of buffalo dung/dropping, there were approximately 166 seeds of A. nilotica. In Baluran National Park, Landsat TM image analysis shows that in fourteen years (2000 - 2014), savanna size has decreased by 1,361 ha. Meanwhile, A. nilotica stands to increase by 1,886 ha (Sutomo and van Etten 2016, unpublished data).

In addition, other environmental factors such as soil nutrients, land-use changes and disturbance agents such as fire also need to be used in consideration with the model. Moreover, our understandings of the capability of $A$. nilotica to adapt to the changes in these factors is still limited (but see Kriticos et al., 2003). Based on their species distribution modelling and climate change projection for A. nilotica (subsp. indicia) in Australia, it is expected that there may be increases in water-use efficiency of the species due to increased atmospheric $\mathrm{CO}^{2}$ concentrations, which allows it to invade more xeric sites further inland and increased temperatures. A. nilotica is frost intolerant, grows in areas where the mean monthly temperature of the coldest month is $16^{\circ} \mathrm{C}$ and it can endure temperatures up to $5^{\circ} \mathrm{C}$ (Kriticos et al. 2003). Conservationists should not be deterred from using the predictive power of SDMs although modelling limitations apply. A dynamic SDM, based on well-surveyed populations responding to changes in known critical parameters, is one of the most excellent tools existing for conservationists to visually suggest future conditions. Users should be aware of limitations, but the model insights are a vital preliminary point for decision making (Carvalho et al. 2011).

Finally, this study is the first to model and highlight regions with a high risk of invasion by invasive alien species A. nilotica in the tropical environment of Southeast Asia, especially central and eastern Indonesia. Future research should endeavor at developing extrapolative modelling based on traits related to invasiveness that can be combined with the current model of estimation of geographic likelihood establishment. More research is needed on how to use SDMs in the service of informing public policy, stakeholders' scenario analysis and applied conservation (Driscol et al. 2012). When SDMs can bring together scientists, public stakeholders, and policy makers, and are used as an adaptive management tool to understand complex landscapes that are undergoing changes, only then it has achieve their full potential (Polunin 2014).

\section{ACKNOWLEDGEMENTS}

We thank School of Sciences, Edith Cowan University, Australia and Bali Botanic Gardens-Indonesian Institute of Sciences (LIPI), as well as Indonesian Ministry of Research and Technology (RISTEK). Thanks also to Sarah Richmond (Griffith University, Australia) and Lee Belbin (Atlas of Living Australia) for introducing the BCCVL. 


\section{REFERENCES}

Adhikari D, Barik SK, Upadhaya K. 2012. Habitat distribution modeling for reintroduction of Ilex khasiana Purk., a critically endangered tree species of north-eastern India. Ecol Eng 40: 37-43. DOI: 10.1016/j.ecoleng.2011.12.004

Aldrian E, Susanto RD. 2003. Identification of three dominan precipitation regions within Indonesia and their relationship to sea surface temperature. Int J Clim 23: 1435-52. DOI: 10.1002/joc.950

Bertelsmeier C, Courchamp F. 2014. Future ant invasions in France. Environ Conserv 41: 217-28. DOI: 10.1017/S0376892913000556

Bond W J, Keeley JE. 2005. Fire as a global 'herbivore': the ecology and evolution of flammable ecosystems. Trends Ecol Evol 20: 387-94. DOI: $10.1016 /$ j.tree.2005.04.025

Brenan JPM. 1983. Manual on taxonomy of Acacia species: present taxonomy of four species of Acacia (A. albida, A.s enegal, A. nilotica A. tortilis). United Nations FAO, Rome.

Burrows WH, Carter JO, Scanlan JC, Anderson ER. 1991. Management of Savannas for Livestock Production in North-East Australia: Contrast across the Tree-Grass Continuum. In: Werner PA (ed) Savanna Ecology and Management. Blackwell Scientific Publication, London.

Carvalho SB, Brito JC, Crespo EG, Watts ME, Possingham HP. 2011 Conservation planning under climate change: toward accounting for uncertainty in predicted species distributions to increase confidence in conservation investments in space and time. Biol Conserv 144: 202030. DOI: 10.1016/j.biocon.2011.04.024

Crego RD, Nielsen CK, Didier KA. 2014. Climate change and conservation implications for wet meadows in dry Patagonia. Environ Conserv 41: 122-31. DOI: 10.1017/S037689291300026X

Djufri. 2004. Acacia nilotica (L.) Willd. ex Del. and its problem in Baluran National Park, East Java. Biodiversitas 5 (2): 96-104. DOI: 10.13057/biodiv/d050211 [Indonesian]

Driscol CT, Lambert KF, Chapin III FS, Nowak DJ, Spies TA, Swanson FJ, Kittredge JDB, Hart CM. 2012. Science and society: the role of long-term studies in environmental stewardship. Bioscience 62: 354 66. DOI: 10.1525/bio.2012.62.4.7

FAO. 2014. Acacia nilotica: a Tree Legume out of Control. Food and Agriculture Organization. Available online at http://www.fao.org/ag/agp/agpc/doc/publicat/gutt-shel/x5556e0v.htm (accessed 15/03/2015)

Fisher R. 2010. Socializing the pixel, mixed methods approach to assessing the state of forests in West Timor. [Dissertation]. Charles Darwin University, Darwin.

Fisher R, Bobanuba WE, Rawambaku A, Hill GJ, Russell-Smith J. 2006. Remote sensing of fire regimes in semi-arid Nusa Tenggara Timur, eastern Indonesia: current patterns, future prospects. Intl J Wildland Fire 15: 307-17. DOI: 10.1071/WF05083

Franklin J, Regan HM, Syphard AD. 2014. Linking spatially explicit species distribution and population models to plan for the persistence of plant species under global change. Environ Conserv 41: 97-109. DOI: $10.1017 / \mathrm{S} 0376892913000453$

GBIF. 2016. Acacia nilotica (L.) Willd. ex Delile. GBIF Secretariat: GBIF Backbone Taxonomy. Available online at: http://www.gbif.org/species/2978421

Gurrutxaga M, Saura S. 2014. Prioritizing highway defragmentation locations for restoring landscape connectivity. Environ Conserv 41: 157-64. DOI: $10.1017 /$ S0376892913000325

Hallgren W, Beaumont L, Bowness A, Chambers L, Graham E, Holewa H, Laffan S, Mackey B, Nix H, Price J. 2016. The Biodiversity and Climate Change Virtual Laboratory: Where ecology meets big data. Environ Model Software 76: 182-6. DOI: 10.1016/j.envsoft.2015.10.025

Hanifah M, 2014, Analysis of Relationship between Rainfall with Distribution and Onset of Hotspots for Early Detection in East Kalimantan Province. [Thesis]. Institut Pertanian Bogor, Bogor. [Indonesian]

Hijmans RJ, Cameron SE, Parra JL, Jones PG, Jarvis A. 2005. Very high resolution interpolated climate surfaces for global land areas. Intl J Clim 25: 1965-78. DOI: 10.1002/joc. 1276

IPCC. 2007. Summary of Policy Makers. In: Solomon S, Qin D, M Manning M, Chen Z, Marquis M, Averyt KB, Tignor M, Miller HS (eds.) Climate Change 2007: the Physical Science Basis. Contribution of Working Group I to the Fourth Assessment Report of the Intergovernmental Panel on Climate Change. Cambridge University Press, Cambridge.

Krebs CJ. 1985. Ecology: The Experimental Analysis of Distribution and Abundance. Harper \& Row, New York.

Kriticos DJ, Sutherst RW, Brown JR, Adkins SW, Maywald GF. 2003. Climate change and the potential distribution of an invasive alien plant: Acacia nilotica ssp. indica in Australia. J Appl Ecol 40: 111-24. DOI: 10.1046/j.1365-2664.2003.00777.x

Mairota P, Leronni V, Xi W, Mladenoff DJ, Nagendra H. 2014. Using spatial simulations of habitat modification for adaptive management of protected areas: Mediterranean grassland modification by woody plant encroachment. Environ Conserv 41: 144-56. DOI: 10.1017/S037689291300043X

Molloy SW, Davis RA, Van Etten EJB. 2013. Species distribution modeling using bioclimatic variables to determine the impacts of a changing climate on the western ringtail possum (Pseudocheirus occidentals; Pseudocheiridae). Environ Conserv 41: 176-86. DOI: 10.1017/S0376892913000337

Molloy SW, Davis RA, van Etten EJB. 2016. Incorporating field studies into species distribution and climate change modeling: A case study of the koomal Trichosurus vulpecula hypoleucus (Phalangeridae). PloS One11: 1-18. DOI: 10.1371/journal.pone.0154161

Monk KA, De Fretes Y, Reksodihardjo-Lilley, Gayatri. 2000. Ecology of Nusa Tenggara and Mollucas. Prenhallindo, Jakarta. [Indonesian].

Polunin NVC. 2014. Editorial: What are the roles of species distribution models in conservation planning? Environ Conserv 4: 93-96. DOI: $10.1017 / \mathrm{S} 0376892913000581$

Radford IJ, Nicholas M D, Brown JR. 2001. Impact of prescribed burning on Acacia nilotica seed banks and seedlings in the Astrebla grasslands of northern Australia. J Arid Environ 49: 795-807. DOI: 10.1006/jare.2001.0846

Reynolds J A, Carter JO. 1990. Woody weeds in central western Queensland. In: Proceedings 6th Biennial Conference, Australian Rangelands Society. Carnarvon, Perth, Australia.

Richmond S, Huijbers C. 2016. Species distribution modeling and climate impact projections. Griffith University, Queensland.

Sheppard CS, Burns BR, Stanley MC. 2014. Predicting plant invasions under climate change: are species distribution models validated by field trials? Glob Change Biol 20: 2800-14. DOI: 10.1111/gcb.12531

Skowno ALM, JJ, Bond WJ, Balfour D. 1999. Secondary succession in Acacia nilotica (L.) savanna in the Hluhluwe Game Reserve, South Africa. Plant Ecol 145: 1-9. DOI: 10.1023/A:1009843124991

Sutomo, van Etten E. 2016. Unfolding Structure of Lowland Seasonal Tropical Dry Forest and Transition of Savanna in Indonesia. In: EcoSummit 2016. Ecological Sustainability: Engineering Change. Elsevier, Montpellier, France, 29 August - 1 September 2016.

Sutomo, van Etten E, Priyadi A. 2015, Do Water Buffalo Facilitate Dispersal of Invasive Alien Tree Species Acacia nilotica in Bekol Savanna Baluran National Park? In: Damayanti EK, Fernandez JC (eds) Second International Conference on Tropical Biology. SEAMEO BIOTROP, Bogor, 12-13 October 2015

Sweets JA. 1988. Measuring the accuracy of diagnostic systems. Science 240: 1285-923. DOI: $10.1126 /$ science. 3287615

Tjitrosoedirdjo S. 2008. Invasive Species Database: Acacia nilotica (L.) Willd. ex Delile. SEAMEO-BIOTROP South East Asian Regional Centre for $\quad$ Tropical Biology, http://kmtb.biotrop.org/collections/spias/detail/2

Tjitrosoedirdjo S, Mawardi I, Setiabudi, Bachri, Tjitrosoediro S. 2013. Chemical control of Acacia nilotica under medium density regime populations and broadleaved weeds in bekol savanna Baluran National Park, East Java Indonesia. In: Bakar, B, Kurniadi D, Tjitrosoediro S. (eds) 24th Asian-Pacific Weed Science Society Conference. BIOTROP, Bandung.

Van Steenis CGGJ. 1972. The Mountain Flora of Java. E.J Brill, Leiden.

Webber BL, Yates CJ, Le Maitre DC, Scott JK, Kriticos DJ, Ota N, McNeill A, Le Roux JJ, Midgley GF. 2011. Modeling horses for novel climate courses: insights from projecting potential distributions of native and alien Australian acacias with correlative and mechanistic models. Divers Distrib 17: 978-1000. DOI: 10.1111/j.1472-4642.2011.00811.x 